\title{
Microstructural Evolution of Al Composite Powders Reinforced by Nano and Micrometric SiC Particles During Mechanical Milling
}

\section{S. Kamrani ${ }^{1,2^{*}}$, R.Riedel ${ }^{2}$ and S.M. Seyed Reihani ${ }^{1}$}

${ }^{1}$ Department of Material Science and Engineering, Sharif University of Technology, 11365-9466, Azadi Avenue 14588 Tehran, Iran ${ }^{2}$ Dispersive Solids Group, Darmstadt University of Technology, Petersenstr.23. D-64287, Germany

\section{Abstract}

Aluminum powder and 5 vol.\% $\mathrm{SiC}$ particles with an average diameter of $50 \mathrm{~nm}$ are milled to produce Al-SiC nanocomposite. Al matrix composite containing 5 vol.\% SiC with the average particle size of $1 \mu \mathrm{m}$ was also produced and characterized to examine the influence of nanometric and micrometric reinforcement particles on the mechanical milling process. It was shown that the presence of hard ceramic particles leads to a faster work-hardening and promotes the onset of the fracture process of $\mathrm{Al}$ particles. The effect of nanometric $\mathrm{SiC}$ on the milling stages was found to be slightly less pronounced as compared with the micrometric SiC. The analysis of XRD patterns revealed that grain refinement occurred faster in the aluminum matrix reinforced with nanometric hard particles.
Publication History:

Received: March 23, 2015

Accepted: May 10, 2015

Published: May 12, 2015

\section{Keywords:}

$\mathrm{Al}-\mathrm{SiC}$, Effect of particle size, Evolution, Mechanical Milling, Nanocomposite, Structural

\section{Introduction}

Development of the modern technologies creates demands for new construction materials with improved mechanical properties, higher corrosion and creep-resistance [1]. Discontinuous reinforced aluminum matrix composites are ranked as one of the most promising materials for structural applications, of which light-weight is crucial [2]. It has been reported [3-6] that by decreasing the reinforcement particle size and the matrix grain size higher mechanical strength is achieved. Smaller particles are less prone to have internal defects and thus are more difficult to be fractured [7]. Additionally, the stress concentration level on each particle is lower as there are more particles bearing applied load, leading to a decrease in the probability of fracturing. Therefore, it is of great interest to use nanoscaled ceramic particles as the reinforcement of metal matrices. Nevertheless, the fabrication of metal matrix nanocomposites (MMNCs) is a challenging task due to difficulties in distributing of the reinforcement particles throughout the metal matrix homogeneously [7]. A very high surface to volume ratio of nanoparticles induces particle agglomeration and clustering, deteriorating the mechanical properties of the composite [8-10].

A look through the literature, for example [11-13], reveals that many works have been performed to improve the distribution of micrometer reinforcement particles into metal matrices. Amongst different procedures, mechanical alloying (MA) has been successfully employed for the fabrication of metal matrix composites [14-17] and metal matrix nanocomposites [18-21]. Naser et al. [22] have shown that this method is a novel approach for dispersion strengthening of metals by nano-oxides where the internal oxidation technique is not applicable. Meanwhile, the procedure is not restricted to nano-oxides, rather than it can be applied to other systems and with any type of reinforcement $[19,23,24]$. Recently, dispersion of SiC nanoparticles in Al-5083 [24], Al-6Ti-6Nb [23], and Mg [19] matrixes by mechanical milling has been investigated. It was shown that the powder particles are trapped between the colliding balls during milling and undergo deformation, welding or fracture, depending on the mechanical behavior of powder components. Therefore, the nanometric particles are distributed throughout the matrix uniformly after a relatively short milling time.

In the present work, the structural evolution during mechanical milling of aluminum powder reinforced with $5 \mathrm{vol} . \% \mathrm{SiC}$ nanoparticles was studied. The effect of the reinforcement particle size, i.e. $50 \mathrm{~nm}$ and $1 \mu \mathrm{m}$, on the morphological changes and mechanical milling stages of aluminum powder are compared. The variation in crystallite size and lattice strain versus the milling time is reported in order to highlight the role of nanometric particles on the grain refinement process of the metal matrix.

\section{Experimental Procedure}

Aluminum powder with an average particle size of $49 \mu \mathrm{m}$ and $99.5 \%$ purity was produced by nitrogen gas atomization process. The shape of the particles is almost spherical with relatively broad particle size distribution. SiC powder with an average size of $50 \mathrm{~nm}$ and $1 \mu \mathrm{m}$ was supplied by Alfa Aesar (Ward Hill, MA, USA). Figure 1 shows the morphology of $\mathrm{SiC}$ particles taken by electron microscopy. The micrometric particles are angular type and the nanometric particles exhibit spherical shape.

Composite mixtures comprising of 5 vol. $\% \mathrm{SiC}$ and $\mathrm{Al}$ powders were prepared by $20 \mathrm{~min}$ blending in a Turbula T2C mixer (Basel, Switzerland). To prevent excessive cold welding during milling, 1.5 wt.\% stearic acid was used as the process control agent (PCA). Mechanical milling was performed in a planetary ball mill using 200 hardened stainless steel balls of $4 \mathrm{~g}$ each. The ratio of ball to powder weight was 10:1. The rotational speed was controlled at $250 \mathrm{rpm}$. A high purity (>99.999\%) argon atmosphere was used to prevent possible oxidation of the new surfaces created on fracturing. The milling experiments were stopped periodically every $120 \mathrm{~min}$ and small amount of the powder was collected for testing. In order to highlight the role of nanometric and micrometric SiC particles, the same procedure was applied for the unreinforced aluminum powder.

The particle size distribution of the milled powders was evaluated by laser particle size analyzer (Mastersizer 2000, Malvern Instruments, UK). The morphological changes of the particles during milling were studied by SEM (SEM S360, Cambridge, UK). The apparent density

"Corresponding Author: Dr. Sepideh Kamrani, Department of Material Science and Engineering, Sharif University of Technology, 11365-9466, Azadi Avenue 14588 Tehran, Iran; E-mail: sepideh.kamrani@tu-berlin.de

Citation: Kamrani S, Riede R, Seyed Reihani SM (2015) Microstructural Evolution of Al Composite Powders Reinforced by Nano- and Micrometric SiC Particles During Mechanical Milling. Int J Metall Mater Eng 1: 105. doi: http:// dx.doi.org/10.15344/2455-2372/2015/105

Copyright: (c) 2015 Kamrani et al. This is an open-access article distributed under the terms of the Creative Commons Attribution License, which permits unrestricted use, distribution, and reproduction in any medium, provided the original author and source are credited. 
Citation: Kamrani S, Riede R, Seyed Reihani SM (2015) Microstructural Evolution of Al Composite Powders Reinforced by Nano- and Micrometric SiC Particles During Mechanical Milling. Int J Metall Mater Eng 1: 105. doi: http://dx.doi.org/10.15344/2455-2372/2015/105

Page 2 of 7
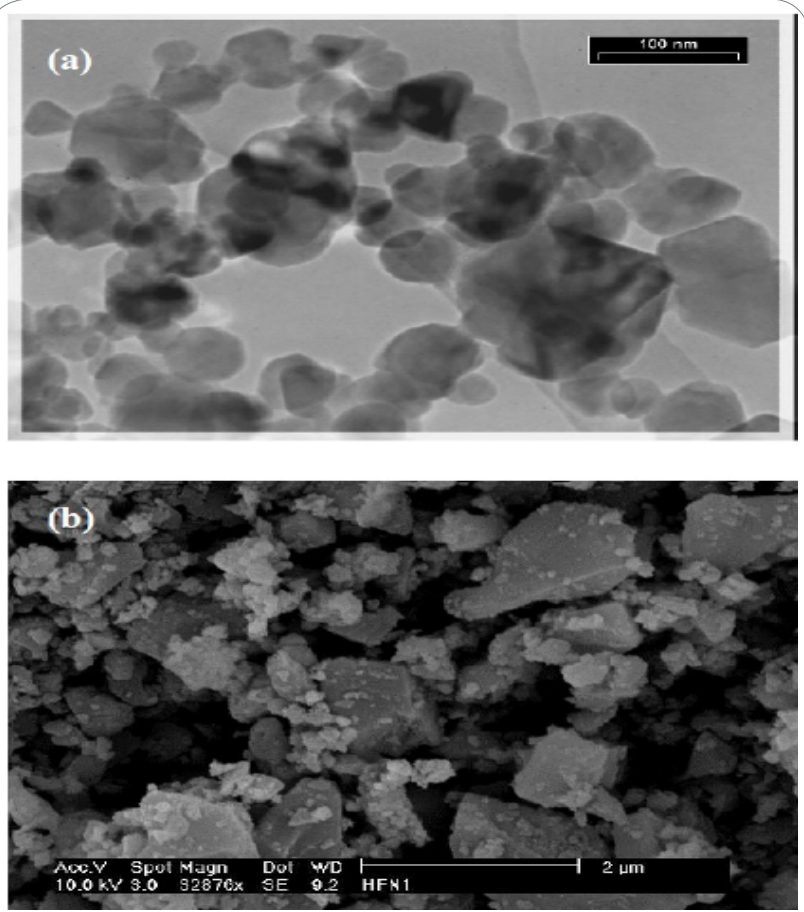

Figure 1: TEM images of nanometric SiC particles (a) and SEM image of micrometric $\mathrm{SiC}$ particles (b). of powders at different stages of milling was measured according to the standard method (ASTM B417). X-ray diffraction (XRD) analysis was employed to determine the crystallite size and the lattice strain. A Philips X'Pert MPD Diffractometer with $\mathrm{Cu} \mathrm{Ka}$ radiation was used. The Williamson-Hall method [25] was used for analyzing the XRD patterns. An annealed $\mathrm{Al}$ powder was used as standard sample for instrumental broadening correction. For microstructural study, the milled powders were cold mounted in a resin, grinded by progressive emery papers, and polished with $1 \mu \mathrm{m}$ diamond paste. The microhardness of the milled powders was measured by Vickers method at $10 \mathrm{~g}$ indenting load.

\section{Results}

\section{Morphology}

SEM was used to study the structural evolution of powder particles during mechanical milling. Selected micrographs at different milling intervals are shown in Figures 2-4. As seen in Figure 2a, the $\mathrm{Al}$ particles exhibit a spherical shape with broad size distribution while small satellite particles attached to the large ones. After $2 \mathrm{~h}$ milling, the initial particles were deformed and a change from spherical to irregular shape was noticed (Figure $2 \mathrm{~b}$ ). The average size of the particles was also increased slightly. At longer milling times, the particles were flattened and flake-like particles were formed (Figure $2 \mathrm{c}$ and $\mathrm{d}$ ). Micro-welding between the particles and the onset of fracture were observed at prolonged milling times.
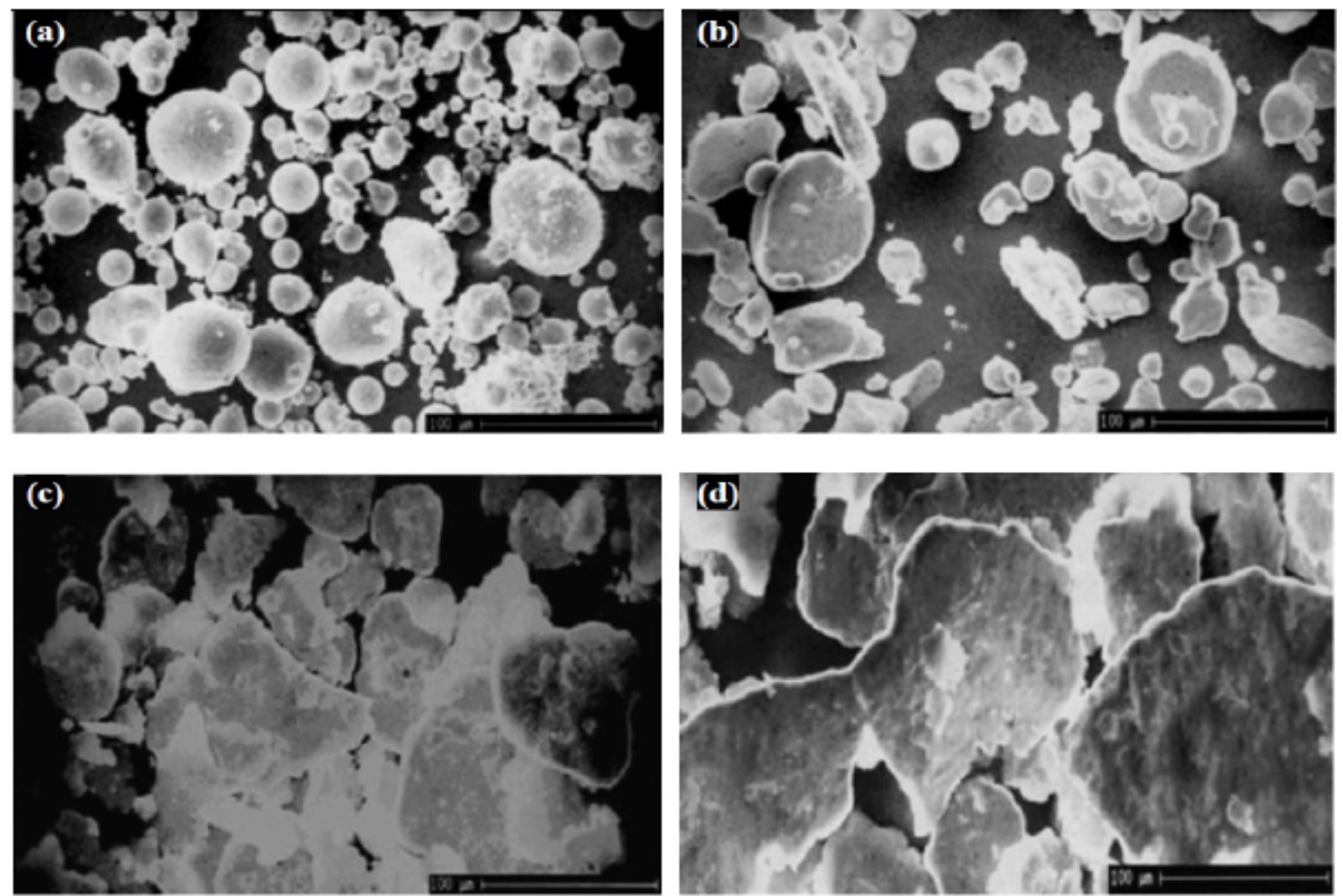

Figure 2: SEM micrographs show the morphology of as-received $\mathrm{Al}(\mathrm{a})$ and milled powder for $2 \mathrm{~h}(\mathrm{~b}), 8 \mathrm{~h}(\mathrm{c})$, and $18 \mathrm{~h}(\mathrm{~d})$. 
Citation: Kamrani S, Riede R, Seyed Reihani SM (2015) Microstructural Evolution of Al Composite Powders Reinforced by Nano- and Micrometric SiC Particles During Mechanical Milling. Int J Metall Mater Eng 1: 105. doi: http://dx.doi.org/10.15344/2455-2372/2015/105

Page 3 of 7

When microscaled $\mathrm{SiC}$ particles were added (Figure 3), the mechanical milling stages had been influenced. At the early stage of milling $(2 \mathrm{~h})$, the effect of hard particles was not pronounced and conspicuous (Figure 3a). After $8 \mathrm{~h}$ milling (Figure $3 \mathrm{~b}$ ), the particles were appeared as irregular grains with high aspect ratio. Many small and irregular particles with relatively low aspect ratio were also seen. At longer milling times, a progressive decrease in the aspect ratio of irregular particles was noticed (Figure 3c) while some equiaxed particles were formed after $14 \mathrm{~h}$ (Figure 3d). As compared with the flake-like $\mathrm{Al}$ particles, the results indicate that welding and fracture proceed faster in the milled composite powder. Meantime, decreasing the $\mathrm{SiC}$ particle size from microscale to nanoscale slightly affected
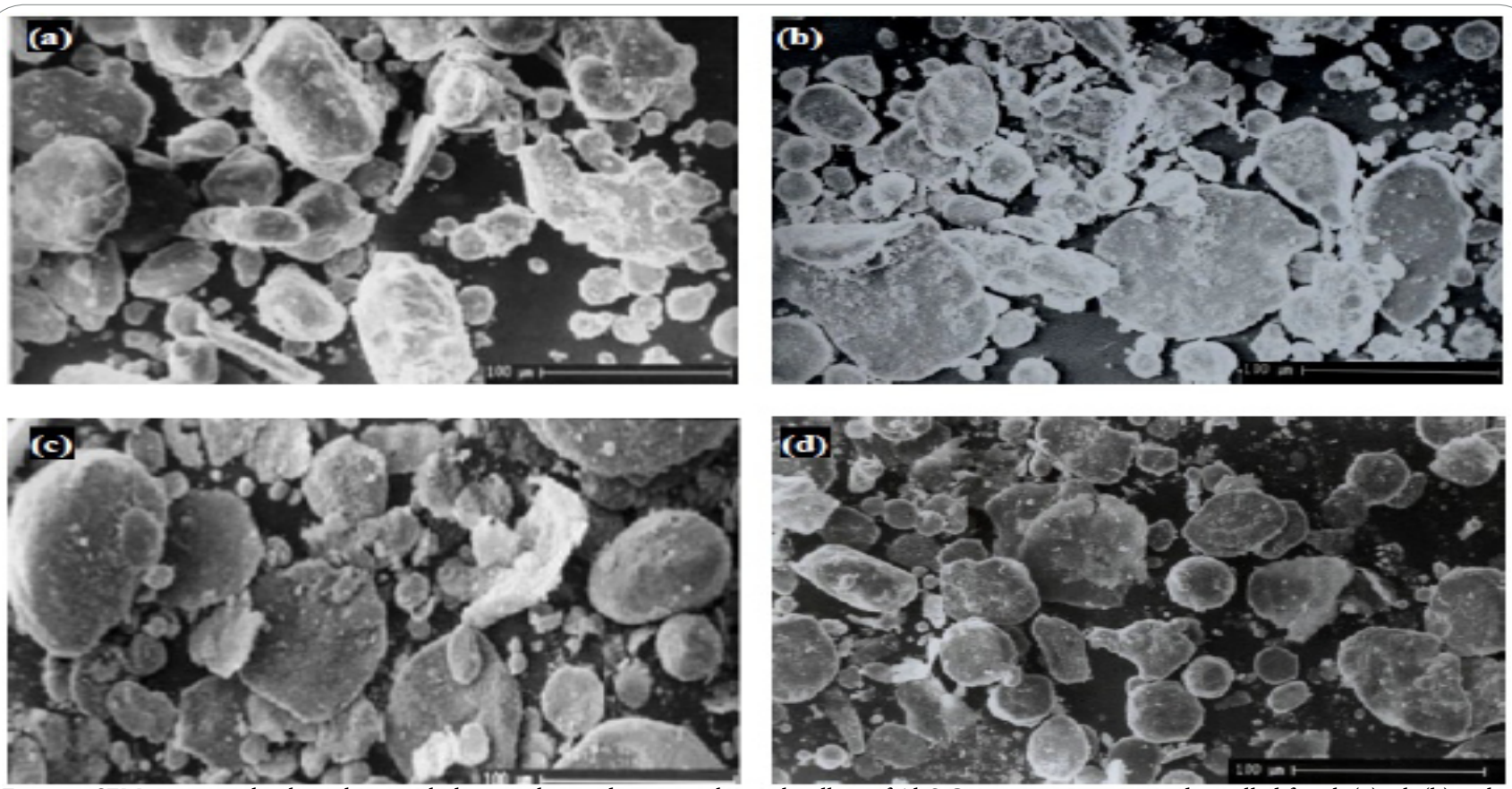

Figure 3: SEM micrographs show the morphology evolution during mechanical milling of Al-SiC microcomposite powder milled for $2 \mathrm{~h}$ (a), $8 \mathrm{~h}$ (b), $12 \mathrm{~h}$ (c), and $14 \mathrm{~h}(\mathrm{~d})$.
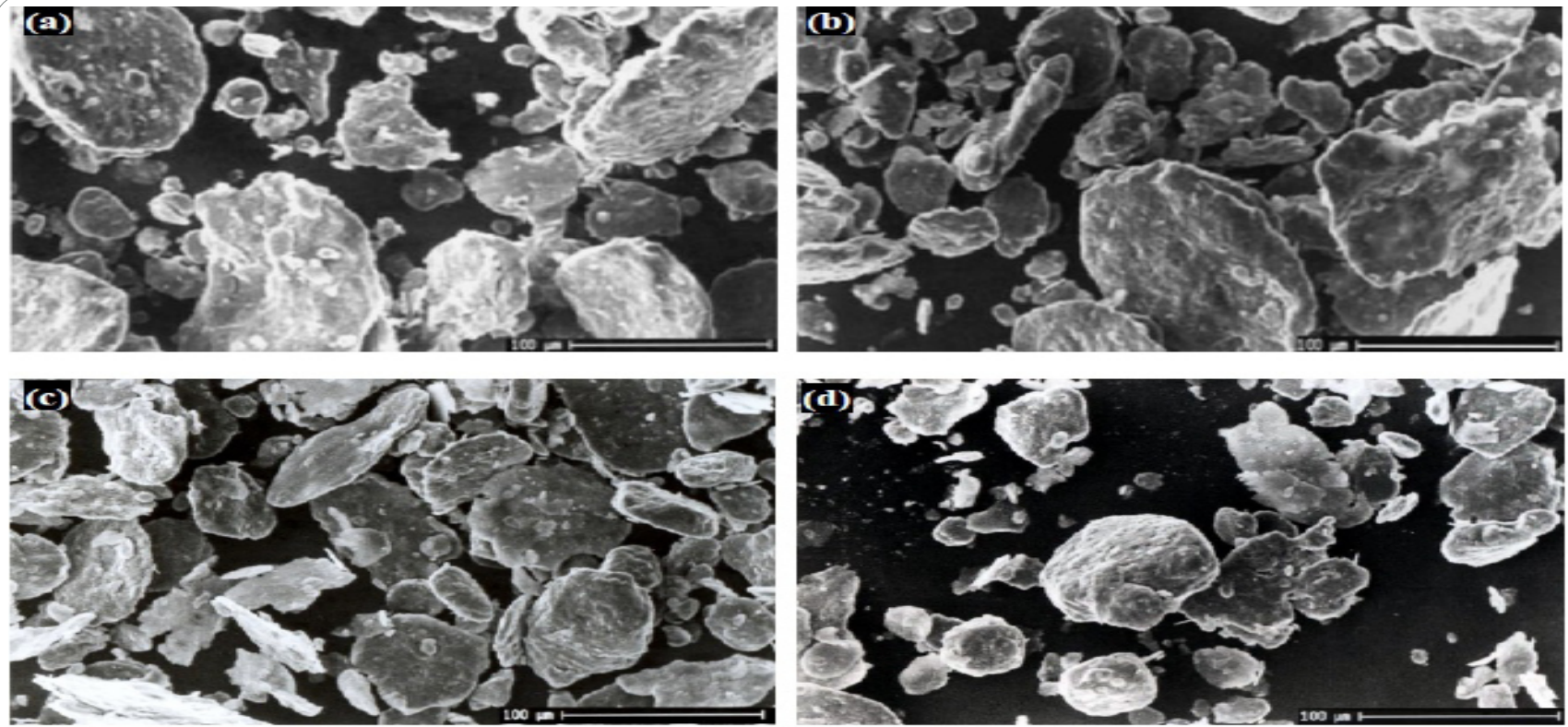

Figure 4: SEM micrographs show changes in morphology of Al-SiC nanocomposite powder milled for 2h (a), 8h (b), 12h (c), and 16h (d).

Int J Metall Mater Eng

ISSN: $2455-2372$

IJMME, an open access journal

Volume 1(1). 2015. 105

the deformation and fracture of the metal matrix upon milling. As Figure 4 shows, at the early stages of milling, particles have undergone deformation (Figure 4a) as similar to the microcomposite powder. The deformation of the particles became more pronounced at longer completely flattened. Further increase in the milling time resulted in a morphological change from laminar to almost equiaxed particles (Figure 4d).

. 
Citation: Kamrani S, Riede R, Seyed Reihani SM (2015) Microstructural Evolution of Al Composite Powders Reinforced by Nano- and Micrometric SiC Particles During Mechanical Milling. Int J Metall Mater Eng 1: 105. doi: http://dx.doi.org/10.15344/2455-2372/2015/105

Page 4 of 7

\section{Particle size distribution}

Figure 5 shows the particle size distribution of mechanically milled $\mathrm{Al}$ and $\mathrm{Al}-\mathrm{SiC}$ composite powders. The particle size distribution of un-milled $\mathrm{Al}$ powder is included in the graph for comparison. The comparative data of the particle size distribution are summarized in Table 1. All the examined powders exhibit a symmetric log-normal size distribution. The higher average particle size of milled Al powder as compared with the gas atomized one is noticeable. In opposite to this observation, the particle size characteristics of the composite powder containing micrometric reinforcement particles are similar to those of the un-milled $\mathrm{Al}$ (Table 1). It appears that the addition of $\mathrm{SiC}$ particles affected the fracture of $\mathrm{Al}$ particles during mechanical milling, because finer and more equiaxed particles were formed at a given milling time (Figures 3 and 4). A symmetrical Gaussian bellshaped distribution in the particle size distribution also indicates the equilibrium between fracture and welding, typical of the final stage of mechanical milling [15]. It is also important to notice the difference between the milled composite powders containing micrometric and nanometric reinforcement particles. As it is seen, the average particle size of the nanocomposite powder is higher than that of the microcomposite. The size distribution is also broader. Figure 6 shows the variation of apparent density of powders as a function of milling time. One can notice the higher density of composite powders compared with the unreinforced Al. The lower density of Al powder is related to the flake-like morphology of its particles. In contrast, the irregular shape particles of the composite powders induce higher packing density. It is also noteworthy that, the apparent density of $\mathrm{Al}-$ $\mathrm{SiC}$ microcomposite is higher than that of the nanocomposite. This observation highlights the effect of reinforcement particle size on the fracture and welding stages occurring upon milling.

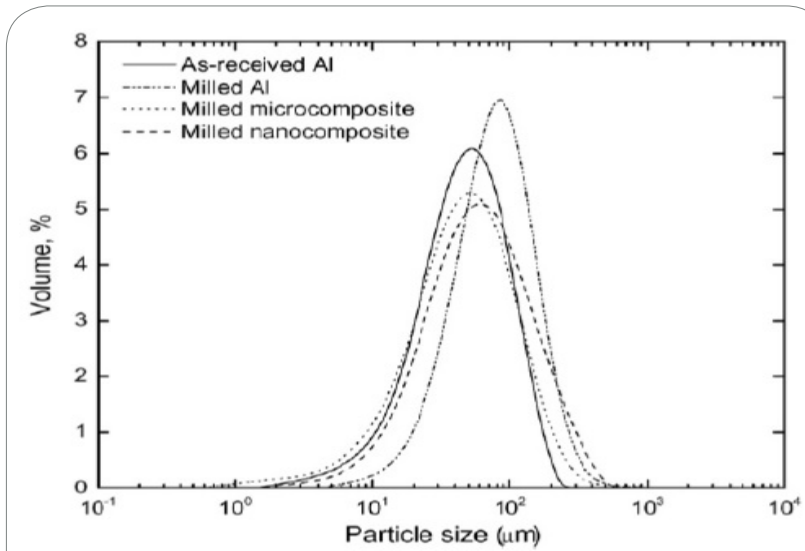

Figure 5: Particles size distribution of milled $\mathrm{Al}$ and $\mathrm{Al}-\mathrm{SiC}$ composite powders for $16 \mathrm{~h}$. The particle distribution of as-received $\mathrm{Al}$ powder is shown for comparison.

\begin{tabular}{|l|l|l|l|l|}
\hline Materials & $\mathrm{D}_{10}$ & $\mathrm{D}_{50}$ & $\mathrm{D}_{90}$ & $\mathrm{D}_{90}-\mathrm{D}_{10}$ \\
\hline Un-milled Al & 16 & 49 & 117 & 101 \\
\hline Milled Al & 35 & 88 & 193 & 158 \\
\hline Al-SiC $(1 \mu \mathrm{m})$ & 12 & 43 & 122 & 110 \\
\hline Al-SiC $(50 \mathrm{~nm})$ & 19 & 62 & 190 & 171 \\
\hline
\end{tabular}

Table 1: Particle size characteristics of gas atomized aluminum and milled powders ${ }^{[\mathrm{a}]}$.

$[a] D_{n}$ is the particle size $(\mathrm{mm})$ at the $\mathrm{n} \%$ of the cumulative curve.

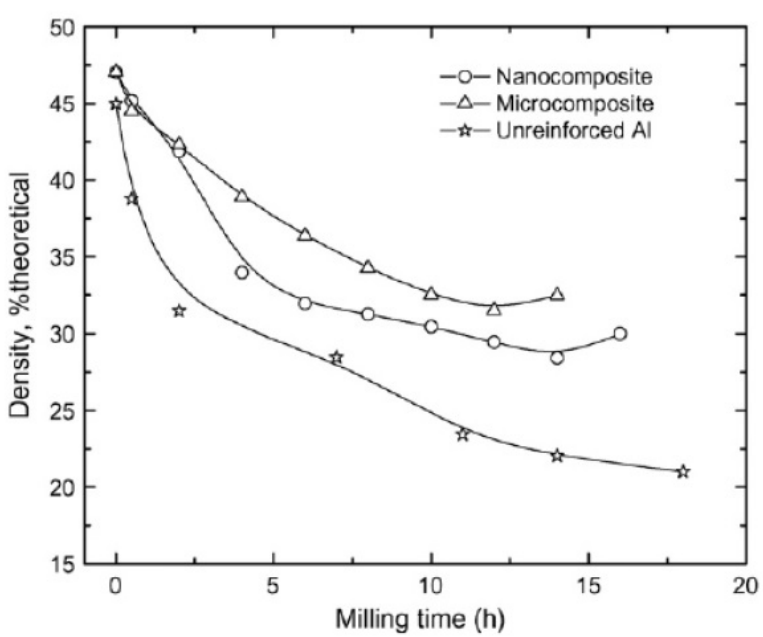

Figure 6: Apparent density (relative to bulk aluminum) of milled powders as a function of milling time.

\section{Microstructure}

The microstructure of milled composite powders is shown in Figure 7. The cellular structure of the particles elongated along the deformation axis is visible. The elongated cellular structure of nanocomposite is finer than that of the microcomposite. Although the $\mathrm{SiC}$ particles were distributed almost uniformly throughout the $\mathrm{Al}$ matrix, the micrometric particles have been refined slightly. The hardness variation versus the milling time is shown in Figure 8. As it is seen, a significant change in the hardness occurred at the early stages of MA. Also, the hardness of nanocomposite powder is higher than that of microcomposite. In order to evaluate the effect of MA on the grain refinement of the $\mathrm{Al}$ matrix depending on the reinforcement particles size, XRD analysis was performed. Figure 9 shows the XRD patterns of the $\mathrm{Al}-\mathrm{SiC}$ composite powders at different milling stages. Peak line broadening represents a decrease in the crystallite size and accumulation of lattice strain. It was found that the effect of nanometric $\mathrm{SiC}$ on the peak broadening was more pronounced than that of the microscaled particles. The analysis of the XRD peaks was performed via the Williamson-Hall method according to the following equation [26]:

$$
\beta_{s} \cos \theta=\frac{k \lambda}{d}+2 \varepsilon \sin \theta
$$

where $\beta_{\mathrm{s}}$ is the sample broadening in radians, $\theta$ the position of peak maximum, $K$ the Scherrer constant $(K=0.9[26]), \lambda$ the $X$-ray wavelength $\left(\lambda_{\mathrm{Cu}}=0.15406 \mathrm{~nm}\right), d$ the crystallite size, and $\varepsilon$ is an approximate upper limit of the lattice distortion. The instrument broadening $(\beta \mathrm{i})$ was removed using the following equation according to Gaussian-Gaussian relationship by an annealed $\mathrm{Al}$ powder:

$$
\beta_{\mathrm{s}}^{2}=\beta_{\mathrm{e}}^{2}-\beta_{\mathrm{i}}^{2}
$$

where $\beta_{\mathrm{e}}$ is the FWHM of the measured XRD peak. The results of $\mathrm{XRD}$ analysis are reported in Table 2 . It is seen that the crystallite size of $\mathrm{Al}$ matrix decreases with increasing the milling time. Furthermore, the grain refinement of the metal matrix occurs faster in the case of nanometric particles whilst the accumulated lattice strain is lower.

\section{Discussion}

It is known that during mechanical milling, plastic deformation, welding, and fracture of the particles are dominant mechanisms 
Citation: Kamrani S, Riede R, Seyed Reihani SM (2015) Microstructural Evolution of Al Composite Powders Reinforced by Nano- and Micrometric SiC Particles During Mechanical Milling. Int J Metall Mater Eng 1: 105. doi: http://dx.doi.org/10.15344/2455-2372/2015/105
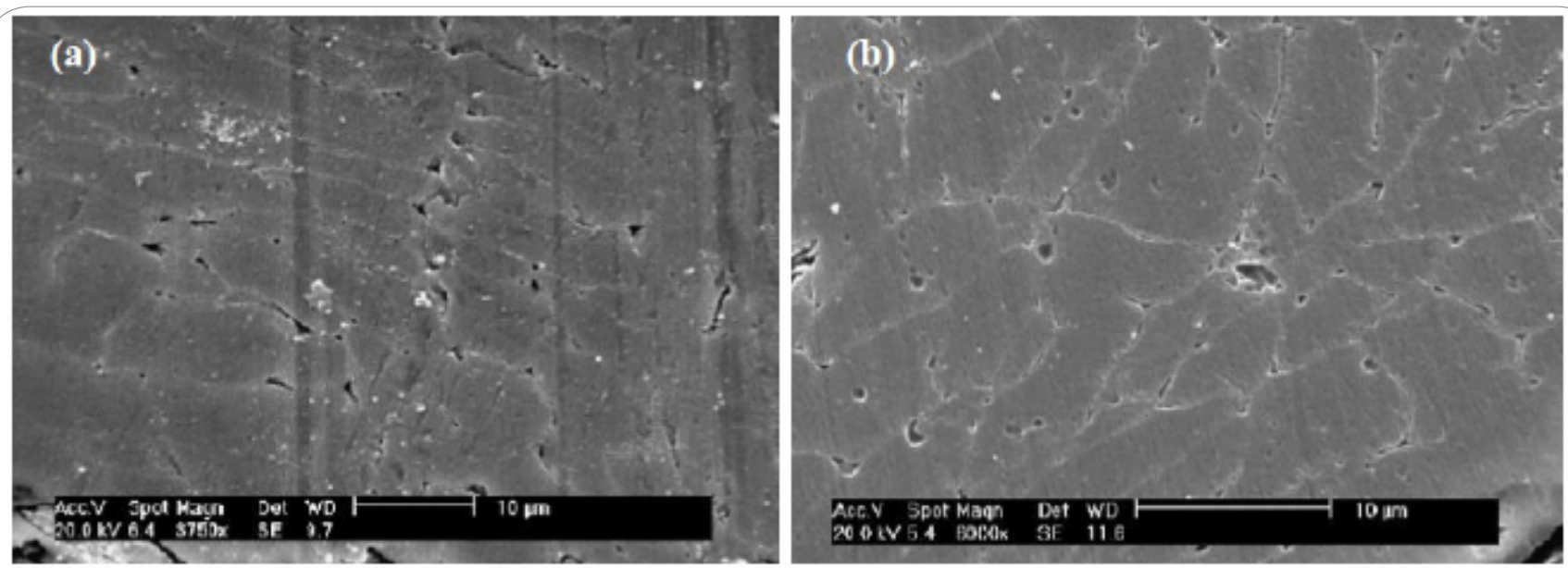

Figure 7: Optical micrographs show the microstructure of mechanically milled Al-SiC nanocomposite (a) and microcomposite (b) powders.

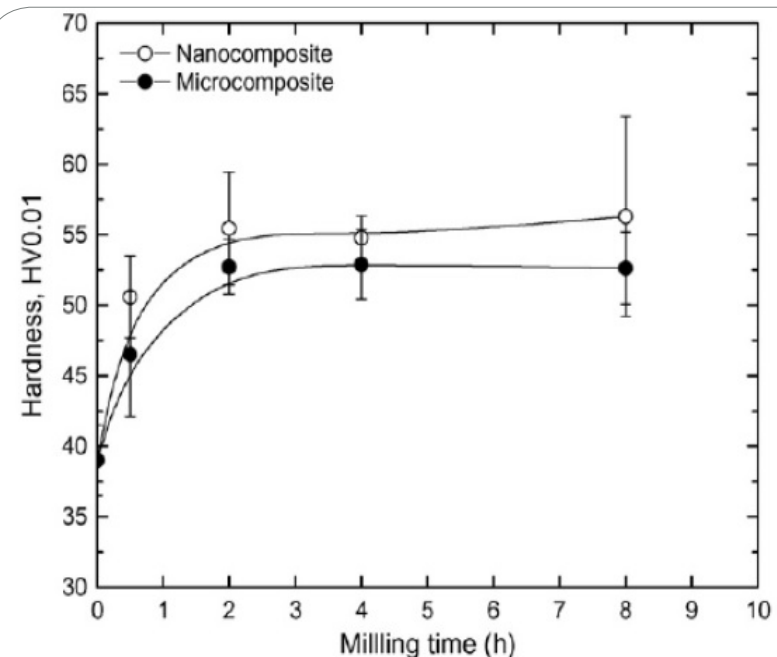

Figure 8: Effect of milling time on the hardness of Al-SiC composite powders.
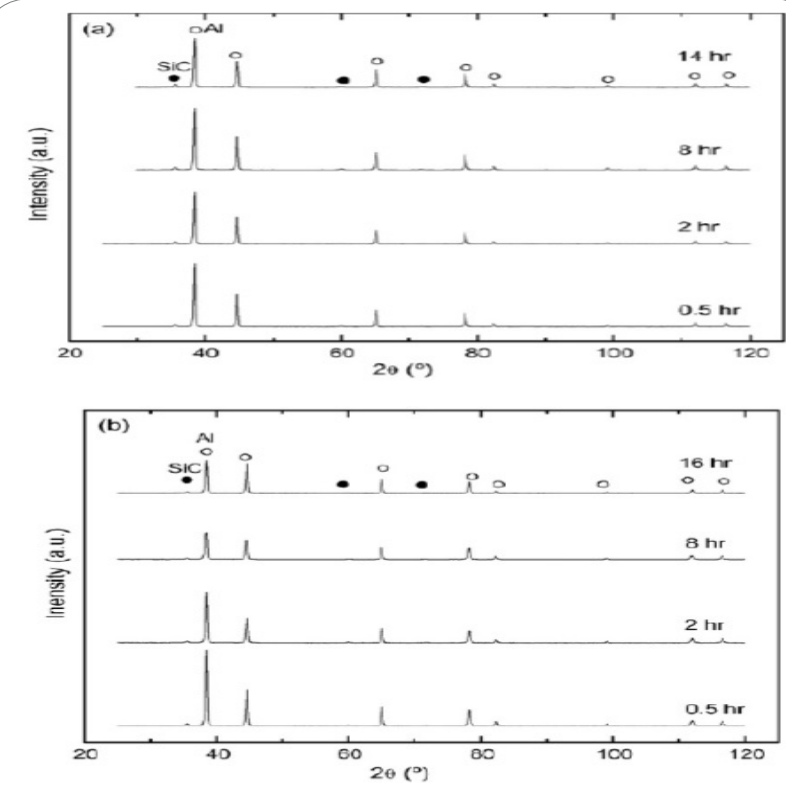

Figure 9: XRD pattern of milled Al-SiC microcomposite (a) and nanocomposite (b) at various times.

\begin{tabular}{|l|l|l|l|}
\hline Sample & $\begin{array}{l}\text { Milling } \\
\text { Time }(\mathrm{h})\end{array}$ & $\begin{array}{l}\text { Crystallite } \\
\text { Size }(\mathrm{nm})\end{array}$ & $\begin{array}{l}\text { Lattice } \\
\text { strain(\%) }\end{array}$ \\
\hline $\mathrm{Al}$ & 16 & 273 & 0.16 \\
\hline $\mathrm{Al}-\mathrm{siC}(50 \mathrm{~nm})$ & 2 & 173 & 0.1 \\
\hline & 8 & 154 & 0.09 \\
\hline & 16 & 138 & 0.09 \\
\hline $\mathrm{Al}-\mathrm{SiC}(1 \mu \mathrm{m})$ & 2 & 462 & 0.18 \\
\hline & 8 & 173 & 0.13 \\
\hline & 14 & 138 & 0.1 \\
\hline
\end{tabular}

Table 2: Crystallite size and lattice strain of Al-SiC composite powder at different milling times.

that influence the characteristics of milled powders [27]. SEM study of the milled $\mathrm{Al}$ powder determined the formation of flakylike particles during MA (Figure 2). Here, the average particle size was found to be significantly higher than that of the gas atomized powder (Table 1). This observation indicates that the deformation and welding of particles are still the predominant mechanisms of milling. In contrast to this finding, a change in the morphology of $\mathrm{Al}$ particles from flake-like to almost equiaxed shape was noticed when $\mathrm{SiC}$ particles were added and a prolonged milling time was applied (Figures 3 and 4). The presence of hard ceramic particles influences the milling stages through three main phenomena including (i) local deformation in the vicinity of hard particles, (ii) work-hardening rate of the matrix, and (iii) fracture toughness of the particles. All these impact the deformation and fracture of the particles upon milling and thus the overall MA process. For instance, Figure 10a shows an optical micrograph taken from a particle of milled Al-SiC $(1 \mu \mathrm{m})$ for $12 \mathrm{~h}$. The ceramic particles are mostly located at or near the interfacial boundaries of the welded aluminum particle. Although the morphology of the particle does not exhibit flake-shape like milled $\mathrm{Al}$, the orientated interfacial boundaries indicate that the steady-state condition had not been reached. Figure 10b shows a SEM picture taken from a particle of milled $\mathrm{Al}-\mathrm{SiC}(50 \mathrm{~nm})$ for $16 \mathrm{~h}$. Relatively homogenous distribution of the reinforcement particles in the matrix is seen. According to the particle size distribution (Table 1) and the variation of apparent density as a function of milling time (Figure 6), it can be deduced that the size of reinforcement particles affects the fracture process. Different sources such as formation of agglomerates of ultrafine particles and the shape-effect of the reinforcement 
Citation: Kamrani S, Riede R, Seyed Reihani SM (2015) Microstructural Evolution of Al Composite Powders Reinforced by Nano- and Micrometric SiC Particles During Mechanical Milling. Int J Metall Mater Eng 1: 105. doi: http://dx.doi.org/10.15344/2455-2372/2015/105

Page 6 of 7

particles (Figure 1) may contribute in difference between the mechanical milling stages of nanocomposites and microcomposites. Anyway, the remarkable difference between the behaviors of two composites was observed at the early stages of milling. Although more detailed characterizations are required to identify the mechanism, it is suggestible that the agglomeration of nanometric reinforcement particles is important parameter which affects the overall milling process.
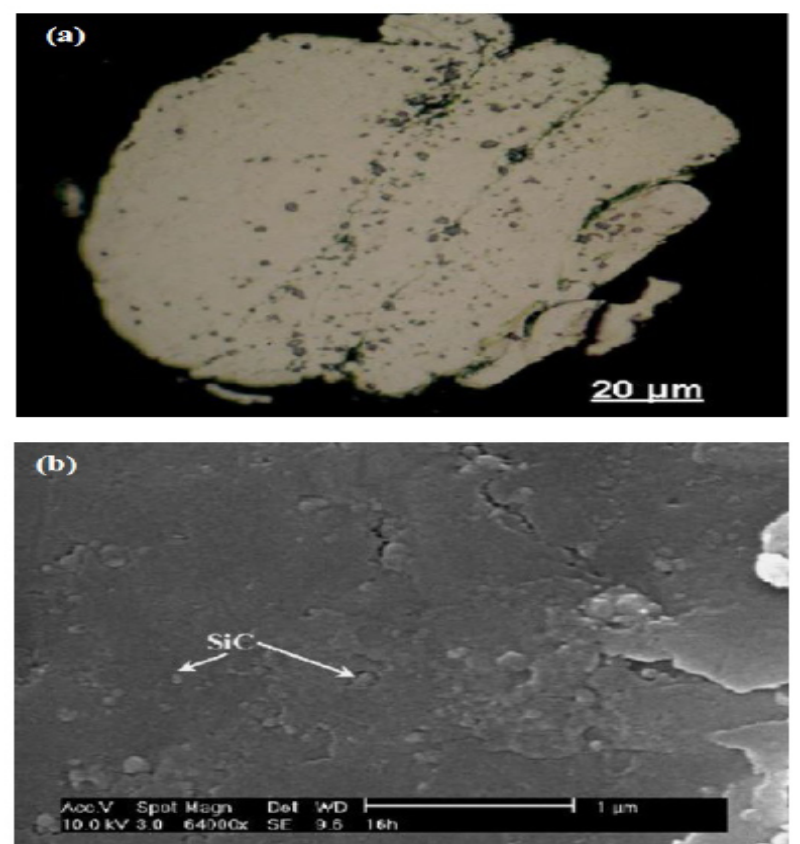
of $\mathrm{SiC}$ particles in the $\mathrm{Al}$ matrix after $14 \mathrm{~h}$ mechanical milling.

Results of structural study by XRD analysis revealed that, the crystallite size of aluminum matrix in the composite powders is smaller than that of the unreinforced aluminum (Table 2). Also, lower crystallite size was obtained when nanometric particles were used. The acceleration of the grain refinement process by adding $\mathrm{SiC}$ particles can be attributed to the generation of a high dislocation activity caused by the interaction between the hard particles and dislocations [28]. Because $\mathrm{SiC}$ particles are hard and non-deformable, they can hinder the dislocations movement, leading to an increase in the dislocation density. When the hard particles are small enough $(<1 \mu \mathrm{m})$, the Orowan bowing mechanism leads to dislocation multiplication [29]. The increased dislocation density accelerates the grain refining progress. Furthermore, the mean free path between the particles decreases as they become smaller, which results in more interaction between dislocations and the obstacles. Hence, the grain refining process in the nanocomposite powder is accelerated.

\section{Conclusion}

Morphological changes during processing of Al-5 vol.\% $\mathrm{SiC}$ nanocomposite powder by high-energy mechanical milling were investigated. The effect of reinforcement particles on the milling stages was studied. The findings can be summarized as followings:

- The size of reinforcement particles influences the milling stages of $\mathrm{Al}-\mathrm{SiC}$ powder mixture during co-milling.
Figure 10: Optical (a) and SEM (b) micrograph shows the distribution

- Morphological study by SEM as well as the apparent density measurement and particle size analysis indicated that the aluminum powder containing nanometric $\mathrm{SiC}$ particles approached a steady-state condition in a longer time compared with micrometric particles. This is possibly due to the presence of agglomerates of ultrafine particles at the early stages of milling.

- A faster grain refinement of the Al matrix containing nanometric particles compared with micrometric particles was noticed during co-milling. This finding suggests that the plastic deformation of the metal matrix is affected by the size of reinforcement particles.

- The hardness of milled Al-SiC powder mixture increases abruptly with increasing the milling time and approaches a plateau at the early stages of the processing. The hardness of powder particles reinforced with nanometric particles was found to be higher than those with micrometric particles, particularly at the early stages of milling.

\section{Competing Interests}

The authors declare that they have no competing interests exit.

\section{Author Contributions}

All the authors substantially contributed to the study conception and design as well as the acquisition and interpretation of the data and drafting the manuscript.

\section{Acknowledgements}

The authors sincerely acknowledge with thanks the High Technology Industries Center, Iranian Ministry of Industries and Mines and Research and Technology Office of Sharif University of Technology for financial support of the research work.

\section{References}

1. Szcezepanik S, Sleboda T (1996) The influence of the hot deformation and heat treatment on the properties of P/M Al-Cu composites. Journal of Materials Processing Technology 60: 729-733.

2. Clyne TW, Whiters PJ (1993) An Introduction to Metal Matrix Composites. Cambridge University Press 280-282.

3. Yang Y, Jie Lan, Xiaochun Li (2004) Study on Bulk Aluminum Matrix Nanocomposite Fabricated by Ultrasonic Dispersion of Nano-sized SiC Particles in Molten Aluminum Alloy. Materials Science and Engineering A 380: 378383.

4. Hassan SF, Gupta M (2005) Development of high performance magnesium nano-composite using nano $\mathrm{Al}_{2} \mathrm{O}_{3}$ as reinforcement. Materials Science and Engineering A 392: 163-168.

5. Lu L, Lai MO, Liang W (2004) Magnesium nanocomposite via mechanochemical milling. Composites Science and Technology 64: 20092014.

6. Ma ZY, Tjong SC, Li YL (1999) The performance of aluminium-matrix composites with nanometric particulate $\mathrm{Si}-\mathrm{N}-\mathrm{C}$ reinforcement. Composites Science and Technology 59: 263-270.

7. Zhang DL, Liang J, Wu J (2004) Erratum to "Processing Ti3Al-SiC nanocomposites using high energy mechanical milling. Materials Science and Engineering A 375-377: 911-916.

8. Slipenyuk A, Kuprin V, Milmana Y, Spowart JE, Miracle DB (2004) Materials Science and Engineering A 381: 165-170.

9. Slipenyuk A, Kuprin V, Milman Y, Goncharuk V, Eckert J (2006) Properties of $\mathrm{P} / \mathrm{M}$ processed particle reinforced metal matrix composites specified by reinforcement concentration and matrix-to-reinforcement particle size ratio. Acta Materialia 54: 157-166.

10. Bhanu Prasad VV, Bhat BVR, Mahajan YR, Ramakrishnan $P(2002)$ Structure-property correlation in discontinuously reinforced aluminium matrix composites as a function of relative particle size ratio. Materials Science and Engineering A 337: 179-186. 
Citation: Kamrani S, Riede R, Seyed Reihani SM (2015) Microstructural Evolution of Al Composite Powders Reinforced by Nano- and Micrometric SiC Particles During Mechanical Milling. Int J Metall Mater Eng 1: 105. doi: http://dx.doi.org/10.15344/2455-2372/2015/105

Page 7 of 7

11. Hashim J, Looney L, Hashmi MSJ (2002) Particle distribution in cast metal matrix composites-Part I. Journal of Materials Processing Technology 123 251-257.

12. Ganguly P, Poole WJ (202) Characterization of reinforcement distribution in homogeneity in metal matrix composites. Materials Science and Engineering A 332: 301-310.

13. Zhao N, Nash P, Yang X (2005) The effect of mechanical alloying on SiC distribution and the properties of 6061 aluminum composite. Journal of Materials Processing Technology 170: 586-592.

14. Fogagnolo JB, Ruiz-Navas EM, Robert MH, Torralba JM (2002) 6061 A reinforced with silicon nitride particles processed by mechanical milling Scripta Materialia 47: 243-248.

15. Fogagnolo JB, Velasco F, Robert MH, Torralba JM (2002) Effect of mechanical alloying on the morphology, microstructure and properties of aluminium matrix composite powders. Materials Science and Engineering A 342: 131-143.

16. Zhang DL (2004) Processing of advanced materials using high-energy mechanical milling. Progress in Materials Science 49: 537-560.

17. Lu L, Lai MO, Ng CW (1998) Enhanced mechanical properties of an Al based metal matrix composite prepared using mechanical alloying. Materials Science and Engineering A 252: 203-211.

18. Csanady A, Sajo I, Szalay JLA, Papp K, Balaton G, et al. (2006) Al-Pb nanocomposites made by mechanical alloying and consolidation. Current Applied Physics 6: 131-134

19. Ferkel H, Mordike BL (2001) Magnesium strengthened by SiC nanoparticles. Materials Science and Engineering A 298: 193-199.

20. Lee HB, Kim SH, Kang SW, Han YH (2003) Characterisation of mechanically alloyed Ti-Al-B nanocomposite consolidated by spark plasma sintering. British Ceramic Transactions 102: 231-236.

21. Sherif El-Eskandarany M (1998) Mechanical solid state mixing for synthesizing of SiCp/Al nanocomposites. Journal of Alloys and Compounds 279: 263-271.

22. Naser J, Riehemann W, Ferkel H (1997) Dispersion hardening of metals by nanoscaled ceramic powders. Materials Science and Engineering A 234236: 467-469.

23. Jia DC (2000) Influence of SiC particulate size on the microstructural evolution and mechanical properties of $\mathrm{Al}-6 \mathrm{Ti}-6 \mathrm{Nb}$ matrix composites. Materials Science and Engineering A 289: 83-90.

24. Tang F, Hagiwara M, Schoenung JM (2005) Microstructure and tensile properties of bulk nanostructured $\mathrm{Al}-5083 / \mathrm{SiCp}$ composites prepared by cryomilling. Materials Science and Engineering A 407: 306-314.

25. Williamson GK, Hall WH (1953) X-ray line broadening from filed aluminium and wolframL'elargissement des raies de rayons $x$ obtenues des limailles d'aluminium et de tungsten Die verbreiterung der roentgeninterferenzlinien von aluminium- und wolframspaenen. Acta Materialia 1: 22-31.

26. Ortiz AL, Shaw L (2004) X-ray diffraction analysis of a severely plastically deformed aluminum alloy, Acta Materialia 52: 2185-2197.

27. Suryanarayana C (2001) Mechanical alloying and milling. Progress in Materials Science 46: 1-184.

28. Chung $\mathrm{KH}, \mathrm{He} J$, hin $\mathrm{DH}$, Schoenung JM (2003) Mechanisms of microstructure evolution during cryomilling in the presence of hard particles. Materials Science and Engineering A356: 23-31.

29. Kang YC, Chan SL (2004) Tensile properties of nanometric Al2O3 particulate-reinforced aluminum matrix composites. Materials Chemistry and Physics 85: 438-443. 